\title{
Persistence of Tenia solium amongst others human Gastro-intestinal parasites in Bamboutos locality (West region-Cameroon)
}

Fokou Raïssa and Nack Jacques*

Department of Animal Organisms Biology, Faculty of Sciences, University of Douala, P.O. Box 24157 Douala, Cameroun.

*Corresponding author email: jacquesnack@yahoo.fr

Original submitted in on $3^{\text {rd }}$ September 2018. Published online at www.m.elewa.org/journals/ on 31st December 2019 https://doi.org/10.35759/JABs.v144.9

\begin{abstract}
Objectives: This study aimed to evaluate the prevalence of intestinal parasites and identify risk factors of their transmission in the population of Bamboutos Locality (west Cameroon).

Methodology and results: The survey was carried out from 1'st of August to 30 th of September 2017 on 240 residents from Batcham and Mbouda districts. Participants were invited to provide a stool sample, and interviewed about socio-demographic aspects, hygiene behaviours, regular deworming. Each stool sample was analyzed by three different methods: direct examination, Formol-ether method and Kato Katz method. Microscopic analyzes revealed six species of intestinal parasites distributed as follow: two Protozoa: Entamoeba histolytica with a prevalence of 41.7\%; Giardia intestinalis (2.5\%) and four Helminths: Tænia solium (8\%), Ascaris lumbricoides (5\%), Trichuris trichiura (0.8\%) and Enterobius vermicularis (0.4\%). Protozoa were the majority with a proportion of $44.2 \%$ against $14.2 \%$ of Helminths. A total of 116 individuals carried at least one species of parasites, an overall prevalence of $48.3 \%$.No statistical difference was found between the two sexes. The infestation was high in the age group 6 to 10 years. Parasitic carriage was mainly related to educational level and hygiene behaviours.

Conclusion and application of results: The study showed a high prevalence of intestinal parasitosis in Bamboutos locality and their relation with several endemic factors that are the non-compliance with hygiene rules such as use of poor quality water for consumption, consumption of unwashed raw vegetables, irregular use of toilets, cleaning the anal area with green leaves... The study also revealed a focus of Tenia solium and efficiency of diagnosis additional techniques (formalin-ether concentration technique and Kato Katz quantitative technique) comparing to direct microscopic method. This work highlights the need to educate community members, particularly those in rural areas, about the hygiene measures necessary to limit the spread of intestinal parasites and the education of medical staff about the use of additional techniques for the certainty diagnosis of gastrointestinal parasitoses.
\end{abstract}

Keywords: Prevalence, human parasitosis, gastro-intestinal, West-Cameroon, Protozoa, Helminths. 


\section{INTRODUCTION}

Currently, little attention is given to gastro-intestinal parasitic diseases compared to other diseases like HIVI AIDS, malaria and atypical pneumonias. However, these infections constitute in tropics a major public health problem because of their high frequency and the large number of asymptomatic carriers (Laamrani et al., 1999; Hamit et al., 2008). More than 3.5 billion people were infested in the World in 2002 by digestive parasites and 450 million were symptomatic (OMS, 2001).The epidemiology of intestinal parasitic infections shows that they affect every age group and in both sexes. However, the most affected are schoolaged children in whom they can generate nutrient deficiency, dehydration, intestinal malabsorption, nervous disturbance, lateness of physical and mental development and mortality (OMS, 1988; Dianou et al., 2004; Kettani et Azzouzy, 2006; Mbuh et al., 2010). In adults, they contribute to reduce work capacity and constitute a major cause of iron deficiency anaemia in pregnant women (Rodriguez et al., 2006; Ostan et al., 2007). Despite recent years' scientific and technological

\section{MATERIALS AND METHODS}

Study area: Bamboutos Division $\left(5^{\circ} 37^{\prime} 60^{\prime \prime} \mathrm{N}, 10^{\circ} 15^{\prime} 0^{\prime \prime}\right.$ $E$ ) is one of the eight divisions the Western Region of Cameroon. The climate is Cameroonian type characterized by two seasons: one dry season (from November to March) and one rainy season (from March to October), with maximum (200 to $300 \mathrm{~mm}$ ) rainfall on July- August. Department has a population of nearly 350,000 inhabitants, on a total area of $1155 \mathrm{~km}^{2}$, a density of about 300 inhabitants per $\mathrm{km}^{2}$. The main economic activities of the locality: agriculture, barnyard breeding and trade (Anonyme, 2017). The survey was conducted in two districts: Batcham $\left(5^{\circ} 32^{\prime} \mathrm{N}, 10^{\circ} 14^{\prime}\right.$ E) and Mbouda ( $\left.5^{\circ} 37^{\prime} \mathrm{N}, 10^{\circ} 15^{\prime} \mathrm{E}\right)$ chosen because of the high density of population.

Study type, period and population: The study was prospective, descriptive and analytic and lasted for a period of 2 months: from August 1 to September 30, 2017. Eligible participants were anyone, of any age and both sexes living in one of the 2 districts and not on any antiparasitic drugs for at least one month before the study.

Samples collection: Participants were selected through a simple random sampling. In order to cover advances, intestinal parasites remain a peculiarity of tropical and subtropical regions where gastroenteritis control actions are made difficult by the cost of infrastructure and lack of population awareness-building projects(Peruzzi et al., 2006, Ouermi et al., 2012; OMS, 2017). Their prevalence is particularly high in rural areas because of favourable weather conditions for the proliferation of parasites, poor living conditions and hygiene, inadequate sanitation and finally poverty (Dianou et al., 2004; Tagajdid et al., 2012; Benouis et al., 2013).Although many studies have been done in this field in Africa (Ouermi et al., Tagajdid et al., 2012; Benouis et al., 2013) and Cameroon (Mbuh et al., 2010; Fouamno et al., 2011; Lehman et al., 2012), in the Bamboutos Division, a predominantly rural and densely populated locality, no studies in the field have been carried out. This study was therefore conducted in order to determine the prevalence of gastrointestinal parasitosis and identify risk factors related to their appearance and their maintenance in this area.

the entire borough, prospecting was carried out in different quarters and the households selected at random. In each registered household, 1 to 3 individuals were randomly selected, each individual having the same probability to be included in the study. After free and informed consent of the respondent (parent for children), a survey sheet was given for filling. The sheet contains two sections which included: Demographic and socio-economic information (age, gender, residence, location and family size), hygienic and environmental factors (housing conditions, ownership and use of latrines, hand washing practice before eating or after defecation, provenance of drinking water). At the end of this interrogation, sampling technique was well detailed and a sterile, labelled, transparent and hermetically sealed plastic pot was delivered to everyone for stool sample. Stool collection was done next morning between $07 \mathrm{H}$ and $08 \mathrm{H}$ using a cooler and samples were transported to Batcham or Mbouda district hospital laboratory for immediate examination.

Laboratory Procedures: In the laboratory, each stool sample was subjected to 04analyzing methods: 
macroscopic examination, direct microscopic examination, Kato-Katz technique and formalin-ether concentration technique (Katz, 1972; OMS, 1983; OMS, 1993; Guillaume, 2007).

\section{RESULTS}

Socio-demographic characteristics of study subjects: A total of 240 individuals ( 146 women and 94 men) aged from 4 months to 70 years were controlled during this investigation. They were divided into 14 age groups with a step of 5 years. The mean age was 24.60 years and the most strongly represented age group was the 6-10 years. The largest number was observed at Batcham with 127 subjects examined against 113 in Mbouda.

Overall and specific prevalence: Overall, intestinal parasitic infection prevalence rate was $48.3 \%$ (116/240). Both helminth and protozoan were found. Overall, intestinal helminth prevalence rate was lower
Statistical analysis: The collected data were registered in an Excel table (Microsoft EXCEL 2007) and exported to SPSS version 20.0 for further analysis. Differences in proportions were determined using the Chi-squared test, level of significance set at $P<0.05$.

than protozoan infection prevalence (Table 1). Six species were identified as follow: two Protozoa: Entamoeba histolytica, Giardia intestinalis and four Helminths: Tænia solium (more prevalent), Ascaris lumbricoides, Trichuris trichiura and the last prevalent Enterobius vermicularis (Table 1). Mixed infections of two or three parasites occurred in $9.5 \%$ of participants. These associations were: E.histolytica/T. solium (4.6\%), E. histolytica/A.lumbricoides (2.5\%), $\quad$. histolytica/G.intestinalis A.lumbricoides/T.solium (0.4\%) and $E$. histolytica/G.intestinalis/T.solium (0.4\%).

Tableau 1: Prevalence of identified parasite species.

\begin{tabular}{l|l|l}
\hline Groups & Species & Prevalence (\%) \\
\hline \multirow{3}{*}{ Protozoa (44.2\%) } & E. histolytica & 41.7 \\
& G. intestinalis & 2.5 \\
\hline & T. solium & 8 \\
Helminths (14.2\%) & A. lumbricoides & 5 \\
& T. trichiura & 0.8 \\
& E. vermicularis & 0.4 \\
\hline
\end{tabular}

Impact of socio-demographic factors on the prevalence of intestinal parasitosis

Influence of the district: no significant difference between the two districts were showed $\left(X^{2}=1.427\right.$; $d d l=1 ; \quad p=0.23$; Table 2), therefore, analysis will continue regardless of the district.

Influence of age: age had no significant influence on the overall prevalence, even ifage group 6-10 years appeared more parasitized than others $\left(X^{2}=10.930\right.$; $d d l=13 ; p=0.62$; Table 2). Specifically, the species E.vermicularis was significantly encountered in a single age group (31-35) unlike others that were ubiquitous.

Influence of sex: No significant difference was observed in the overall parasite prevalence by gender (Table 2; $X^{2}=0.022 ; d d l=1 ; p=0.88$ ). Nevertheless, the species $T$. trichiura was only encountered in the male gender, unlike other species.

Influence of occupation: No significant difference was also obtained among people from different occupations $\left(X^{2}=24.256 ; d d l=3 ; p=0.135 n s ;\right.$ Table 2).
Influence of school level: individuals with a higher level of education were statistically less parasitized $(22.2 \%)$ than those with primary and secondary school levels with respective rates of $53.4 \%$ and $50.5 \%$ $\left(X^{2}=8.355 ; d d l=3 ; p=0.048 ;\right.$ Table 2).

Impact of hygienic factors on the prevalence of intestinal parasitosis

Influence of drinking water source: individuals drinking well water were significatively more parasitized $(67.1 \%)$ than those drinking faucet one whose infection rate was $29 \%\left(x^{2}=23.479\right.$; $d d l=4 ; p<0.01$; Table 3$)$.

Hand washing practice before eating: this hygiene practice showed a significant influence on the overall prevalence $\left(X^{2}=5.902 ; d d l=2 ; p=0.04\right)$. Individuals who do not wash their hands before eating were the most affected with an infection rate of $60.9 \%$ compared to those who wash their hands with soap and without whose respective rates were $36.4 \%$ and $51.7 \%$ (Table 3).

Raw vegetables washing before consumption: individuals washing raw vegetables before consumption 
were less parasitized $(37.8 \%)$ compared to those who do not wash with a prevalence of $63.9 \%$. This difference of infestation rate is highly significant $\left(X^{2}=15.833\right.$; $\mathrm{ddl}=1 ; \mathrm{p}<0.01$; Table 3).

Type of toilet used: individuals living in concessions without toilets were more infected with a rate of $100 \%$. The least parasitized were those using modern and semi-modern toilets whose infection rates were $43.8 \%$ and $36.6 \%$. This infestation rate is very significant $\left(X^{2}=24.231 ; d d l=3 ; p<0.01 ;\right.$ Table 3).

Hand washing practice after defecating: People who did not wash their hands after defecating were more infested during the study with an infestation rate of $83.3 \%$ compared to $25.5 \%$ and $49.7 \%$, respective prevalence for people washing their hands with and without soap. This hygiene practice showed a very significant influence on the overall prevalence $(P<0.01)$. Influence of anal area cleaning: individuals who use green leaves for the anal area cleaning were more parasitized (68.3\%).The less parasitized individuals were those using both water and paper for this purpose $(28.3 \%)$. This infestation rate was very significant $\left(X^{2}=14.746 ; d d l=3 ; p<0.01\right.$; Table 3).

Impact of regular deworming practice on the prevalence of intestinal parasitosis:

Individuals who regularly use preventive chemotherapy were less infested $(29.1 \%)$ than those who did it only after medical prescription (64.6\%). This practice showed a very significant influence on the overall prevalence $\left(X^{2}=30.111 ; d d=1 ; p<0.01\right.$; Table 3$)$.

Variation of the infestation index according to different diagnostic techniques: Direct microscopic examination alone revealed an overall positivity rate of $31.25 \%$ (75/240) during the study. The additional techniques therefore allowed recovery of 41 samples falsely negative to this first method. In absence of these complementary techniques, the error rate is then $35.30 \%$. 
Table 2: Influence of socio-demographic factors on the overall prevalence

\begin{tabular}{|c|c|c|c|c|}
\hline Variables & $\begin{array}{l}\text { Positive cases } \\
N\end{array}$ & $\begin{array}{l}\text { Negative cases } \\
\mathrm{N} \%\end{array}$ & $\begin{array}{cc} & \text { Total } \\
\mathrm{N} & \% \\
\end{array}$ & $\begin{array}{l}\text { Chi-square } \\
\text { test }\end{array}$ \\
\hline $\begin{array}{l}\text { District } \\
\text { Mbouda } \\
\text { Batcham }\end{array}$ & $\begin{array}{ll}50 & 44.2 \\
66 & 52 \\
\end{array}$ & $\begin{array}{ll}63 & 55.8 \\
61 & 48 \\
\end{array}$ & $\begin{array}{ll}113 & 47.1 \\
127 & 52.9 \\
\end{array}$ & $\begin{array}{l}X^{2}=1.42 ; d d l=1 ; \\
p=0.23 n s\end{array}$ \\
\hline $\begin{array}{l}\text { Age group } \\
{[4 \mathrm{M}-5]} \\
{[6-10]} \\
{[11-15]} \\
{[16-20]} \\
{[21-25]} \\
{[26-30]} \\
{[31-35]} \\
{[36-40]} \\
{[41-45]} \\
{[46-50]} \\
{[51-55]} \\
{[56-60]} \\
{[61-65]} \\
{[66-70]}\end{array}$ & $\begin{array}{cl}17 & 48.6 \\
25 & 59.5 \\
19 & 57.6 \\
11 & 57.9 \\
5 & 38.5 \\
6 & 30 \\
3 & 33.3 \\
5 & 50 \\
7 & 41.2 \\
5 & 55.6 \\
5 & 38.5 \\
1 & 33.3 \\
4 & 51.1 \\
3 & 30 \\
\end{array}$ & $\begin{array}{ll}18 & 51.4 \\
17 & 40.5 \\
14 & 42.4 \\
8 & 42.1 \\
8 & 61.5 \\
14 & 70 \\
6 & 66.7 \\
5 & 50 \\
10 & 58.8 \\
4 & 44.4 \\
8 & 61.5 \\
2 & 66.7 \\
3 & 42.9 \\
7 & 70\end{array}$ & $\begin{array}{cl}35 & 14.6 \\
42 & 17.5 \\
33 & 13.7 \\
19 & 8 \\
13 & 5.4 \\
20 & 8.3 \\
9 & 3.7 \\
10 & 4.2 \\
17 & 7.1 \\
9 & 3.7 \\
13 & 5.4 \\
3 & 1.2 \\
7 & 3 \\
10 & 4.2\end{array}$ & $\begin{array}{l}x^{2}=10.930 \\
d d l=13 \\
p=0.62 n s\end{array}$ \\
\hline $\begin{array}{l}\text { Gender } \\
\text { Female } \\
\text { Male }\end{array}$ & $\begin{array}{ll}70 & 47.9 \\
46 & 48.9 \\
\end{array}$ & $\begin{array}{ll}76 & 52.1 \\
48 & 51.1 \\
\end{array}$ & $\begin{array}{cc}146 & 60.8 \\
94 & 39.2 \\
\end{array}$ & $X^{2}=0.022 ; d d l=1 ; p=0.88 n s$ \\
\hline $\begin{array}{l}\text { Occupation } \\
\text { Students } \\
\text { Traders+resourcefuls } \\
\text { Famers+house keepings } \\
\text { Civil servants }\end{array}$ & $\begin{array}{ll}65 & 57.1 \\
15 & 50 \\
25 & 38.5 \\
& \\
11 & 35.5 \\
\end{array}$ & $\begin{array}{ll}49 & 42.9 \\
15 & 50 \\
40 & 61.5 \\
& \\
20 & 64.5 \\
\end{array}$ & $\begin{array}{ll}114 & 47.5 \\
30 & 12.5 \\
65 & 27.1 \\
& \\
31 & 12.9 \\
\end{array}$ & $\begin{array}{l}X^{2}=24.256 ; d d l=3 ; \\
p=0.135 \mathrm{~ns}\end{array}$ \\
\hline $\begin{array}{l}\text { School level } \\
\text { Uneducated } \\
\text { Primary } \\
\text { Secondary } \\
\text { Higher }\end{array}$ & $\begin{array}{lc}4 & 28.6 \\
55 & 53.4 \\
53 & 50.5 \\
4 & 22.2 \\
\end{array}$ & $\begin{array}{ll}10 & 71.4 \\
48 & 46.6 \\
52 & 49.5 \\
14 & 77.8 \\
\end{array}$ & $\begin{array}{ll}14 & 5.8 \\
103 & 42.9 \\
105 & 43.8 \\
18 & 7.5 \\
\end{array}$ & $\begin{array}{l}X^{2}=8.355 ; d d l=3 ; \\
p=0.048^{*}\end{array}$ \\
\hline Total & $\begin{array}{ll}116 & 48.3\end{array}$ & $\begin{array}{ll}124 & 51.7\end{array}$ & $\begin{array}{ll}240 & 100\end{array}$ & \\
\hline
\end{tabular}


Table 3: Influence of hygienic factors on the prevalence of intestinal parasitosis

\begin{tabular}{|c|c|c|c|c|}
\hline Variables & $\begin{array}{l}\text { Positive case } \\
\mathrm{N} \%\end{array}$ & $\begin{array}{l}\text { Negative case } \\
N \quad \% \\
N\end{array}$ & $\begin{array}{l}\text { Totals } \\
\begin{array}{l}\mathrm{N} \% \\
\end{array}\end{array}$ & Chi-square test \\
\hline $\begin{array}{l}\text { Drinking water source } \\
\text { CDE } \\
\text { Drilling } \\
\text { Well } \\
\text { Marigot } \\
\text { Others } \\
\end{array}$ & $\begin{array}{cc}19 & 29.2 \\
14 & 60.9 \\
49 & 67.1 \\
7 & 58.3 \\
27 & 40.3 \\
\end{array}$ & $\begin{array}{cc}46 & 70.8 \\
9 & 39.1 \\
24 & 32.9 \\
5 & 41.7 \\
40 & 59.7 \\
\end{array}$ & $\begin{array}{ll}65 & 27.1 \\
23 & 9.6 \\
73 & 30.4 \\
12 & 5 \\
67 & 27.9 \\
\end{array}$ & $\begin{array}{l}x^{2}=23.479 ; d d l=4 ; \\
p<0.01^{*}\end{array}$ \\
\hline $\begin{array}{l}\text { Hand washing } \\
\text { With soap } \\
\text { Without soap } \\
\text { No }\end{array}$ & $\begin{array}{ll}24 & 36.4 \\
78 & 51.7 \\
14 & 60.9 \\
\end{array}$ & $\begin{array}{cc}42 & 63.6 \\
73 & 48.3 \\
9 & 39.1 \\
\end{array}$ & $\begin{array}{ll}66 & 27.5 \\
151 & 62.9 \\
23 & 9.6 \\
\end{array}$ & $\begin{array}{l}X^{2}=5.902 ; d d=2 ; \\
p=0.04^{*}\end{array}$ \\
\hline $\begin{array}{l}\text { Raw vegetables washing } \\
\text { Yes } \\
\text { No }\end{array}$ & $\begin{array}{ll}54 & 37.8 \\
62 & 63.9\end{array}$ & $\begin{array}{ll}89 & 62.2 \\
35 & 36.1\end{array}$ & $\begin{array}{cc}143 & 59.6 \\
97 & 40.4\end{array}$ & $\begin{array}{l}X^{2}=15.833 ; d d l=1 ; \\
P<0.01^{*}\end{array}$ \\
\hline $\begin{array}{l}\text { Type of toilet } \\
\text { Modern } \\
\text { Traditional } \\
\text { Semi-modern } \\
\text { Absent }\end{array}$ & $\begin{array}{rl}7 & 43.8 \\
53 & 67.9 \\
52 & 36.6 \\
4 & 100 \\
\end{array}$ & $\begin{array}{rl}9 & 56.2 \\
25 & 32.1 \\
90 & 63.4 \\
0 & 0 \\
\end{array}$ & $\begin{array}{lc}16 & 6.6 \\
78 & 32.5 \\
142 & 59.2 \\
4 & 1.7 \\
\end{array}$ & $\begin{array}{l}x^{2}=24.231 ; d d l=3 ; \\
p<0.01^{*}\end{array}$ \\
\hline $\begin{array}{l}\text { Anal region cleaning } \\
\text { Hygienic paper } \\
\text { Water+paper } \\
\text { Tissue } \\
\text { Green leaves } \\
\end{array}$ & $\begin{array}{ll}71 & 42 \\
2 & 28.6 \\
0 & 0 \\
43 & 68.3 \\
\end{array}$ & $\begin{array}{cc}98 & 58 \\
5 & 71.4 \\
1 & 100 \\
20 & 31.7 \\
\end{array}$ & $\begin{array}{cl}169 & 70.4 \\
7 & 3 \\
1 & 0.4 \\
63 & 26.2 \\
\end{array}$ & $\begin{array}{l}x^{2}=14.746 ; d d l=3 ; \\
p<0.01^{*}\end{array}$ \\
\hline $\begin{array}{l}\text { Regular deworming } \\
\text { Yes } \\
\text { No }\end{array}$ & $\begin{array}{ll}32 & 29.1 \\
82 & 64.6\end{array}$ & $\begin{array}{ll}78 & 70.9 \\
46 & 35.4\end{array}$ & $\begin{array}{ll}110 & 45.8 \\
130 & 57.2\end{array}$ & $\begin{array}{l}x^{2}=30.111 ; d d l=1 ; \\
p<0.01^{*}\end{array}$ \\
\hline Total & $\begin{array}{ll}116 & 48.3 \\
\end{array}$ & $124 \quad 51.7$ & $240 \quad 100$ & \\
\hline
\end{tabular}




\section{DISCUSSION}

The main objective of this study was to determine the prevalence of intestinal parasites in this locality using three methods, including a direct microscopic examination, the Kato-Katz method and the formalinether concentration technique. These microscopic analyses revealed 116 individuals carrying at least one species of parasites, an overall prevalence of $48.3 \%$. This value is similar to those obtained by Fouamno et al. (2011) which were $50.9 \%$ and $51.5 \%$ respectively in Kake and Barombi, two localities of Southwest Cameroon. Otherwise, these results are higher than those presented by Mbuh et al. (2010) who obtained a prevalence of $21 \%$ in Buea urban areas and those obtained by Lehman et al.(2012) who found a prevalence of $26.6 \%$ for intestinal parasites in the city of Douala and its rural area (Njombé). On the other hand, other studies have reported higher prevalences than this value: $60.82 \%$ in Ouagadougou, Burkina Faso (Ouermi et al., 2012) and $73.35 \%$ in the population of N'Djamena (Kostoingue et al., 2002).This difference could be because the diagnosis or study methods used are not the same. In addition, study periods and study frameworks are different. The most common parasite species identified in this study was Entamoeba histolytica with a prevalence of $41.5 \%$, followed by $T$. solium (8\%). This observation is similar to that made by Hamit et al. (2008) in N'Djamena who obtained during their survey a predominance of Entamoeba histolytica with a prevalence of $30.3 \%$. Similarly, Faye et al. (1998) in Dakar and Ouermi et al. (2012) in Ouagadougou obtained a preponderance of Entamoeba histolytica with respectively $47.7 \%$ and $39.88 \%$. The high rate of this parasite could be due to the presence of resistant cysts in the environment as well as abundance of flies, incriminated in their dissemination during the study period (rainy season). The high frequency of $T$. solium will probably be due to the enhanced consumption of undercooked pork in the locality. The study secondly aimed to identify risk factors associated to the transmission of intestinal parasitosis in Bamboutos Division. Based on the districts, no significant difference was found between infestation rates. This insignificance can be justified by the free movement of people between the two boroughs and permanent exchanges (markets, obsequies, agricultural self-help groups) that would consequently make that department a homogeneous entity regarding intestinal parasitosis. According to age groups, although the difference of observed infection rate was not significant $(p=0.62)$, the most infected individuals were those aged from 6 to
10 years $(59.5 \%)$. These results are in line with those obtained by Mbuh et al. (2010) in Buea and those of Lehman et al. (2012) in Douala who note in their studies that, most parasitized age groups were 6 to 12 years and 6 to 10 years respectively. This observation could be explained by the fact that at this age, children become less and less overseen by parents and are engaged in activities that would expose them to more infections. Based on occupation, statistical analyzes revealed no significant difference in infestation $(P=0$, 135). This observation could be explained by absence of a clear separation between occupations in the area. In fact, individuals of all professional categories recognized during the study also engaging in agricultural activities. A significant difference was observed in parasite prevalence by study level $(p=$ 0.04).The least infected were people with a higher education level with a prevalence of $22.2 \%$. This low rate in upper-level individuals could be explained by the fact that they are aware of risks due to exhibition to parasites. The analysis of infestation rate according to drinking water source showed that individuals who consume well water were more parasitized with prevalence of $67.1 \%$, followed by those who consume borehole water whose prevalence was $60.9 \%$.This result corroborates that of Adoubryn et al. (2001) who observed during their study in Toumodi that the most affected individuals were those who consume well water and river water ( $41.2 \%$ and $43.75 \%$ respectively) ; because the surrounding environment is often very unclean, there is stagnant water that infiltrates the soil and ensures the contamination of these water sources. In addition, most of these water points are built near septic tanks. Regarding the type of toilet used, a high prevalence was noted in individuals living without toilets $(100 \%)$ while people with modern toilets were parasitized only on $43.8 \%$. These observations join those of Aksoy et al. (2005) in Turkey and Soumana et al. (2016) in Niger who realized in their studies that families without latrines were significantly more infested than others. Similar studies in Morocco have shown that the presence of a septic tank (modern toilet) has a protective effect against intestinal parasites (Laamrani et al., 1999). The cleaning of the anal area and hand washing after defecation, studied in this work showed very significant differences ( $p<0.01$ ). In fact, individuals using green leaves for faecal hygiene and those who did not wash their hands after defecation were more parasitized with respective rates of $68.3 \%$ and $83.3 \%$. This observation is related to the very close contact 
between the fingers and the faecal matter. Individuals who regularly deworm had low prevalence $(29.1 \%)$, compared to those who rarely or never do it $(64.6 \%)$. Statistical analysis of these results made it possible to note a positive relationship between parasite index and deworming. Although weak, the presence of infested individuals among those who are deworming could be explained by the fact that most of drugs used were anthelmintics. Complementary techniques (formalinether concentration technique and Kato Katz

\section{CONCLUSION}

This study shows high prevalence of intestinal parasitoses for dwellers of Bamboutos locality, with very heavy parasite loads being concentrated in a few individuals. Parasitism was mainly related to several endemic factors, such as: substandard living conditions and lack of personal hygiene, both at the individual and

\section{REFERENCES}

Laamrani A I E, Idrissi A, Lyagoubi M, Barkia A, Ayoujil $M$ et Mahjour J, 1999. Prévalence des parasitoses intestinales au niveau de trois provinces au Maroc. Revue de la Santé méditerranéenne orientale, $1: 86-102$.

Hamit M, Tidjani M and Bilong Bilong C, 2008. Recent data on the prevalence of intestinal parasites in N'Djamena, Chad Republic. African Journal of Environmental Science Technology, 12: 407-411.

OMS, 2001. Burden of disease in disability-adjusted life years by cause, sex and mortality stratum in WHO regions, estimates for 2000, 95P.

Mbuh J V, Ntonifor $\mathrm{H} \mathrm{N}$ and Ojong J T, 2010.The incidence, intensity and host morbidity of human parasitic protozoan infections in gastrointestinal disorder outpatients in Buea Sub Division, Cameroon. Journal Infections Development Countries, 4 (1): 038-043.

Dianou D, Poda J-N, Savadogo L G, Sorgho H, Wango $S P$ et Sondo B, 2004. Parasitoses intestinales dans la zone du complexe hydroagricole du Sourou au Burkina faso.la revue en sciences de l'environnement, $2: 5 p$.

Kettani E I S et Azzouzi E M, 2006.Prévalence des helminthes au sein d'une population rurale utilisant les eaux usées à des fins agricoles à Settat (Maroc). Cahiers d'études et de recherches francophones/Santé, 4 : 245-261. quantitative technique) resulted in the recovery of 41 false-negative direct examinations. This observation is similar to that made by Hamit et al. (2017) in two ecological Chad zones. They found that the direct observation method only covered $65.3 \%$ of the efficiency of Kato Katz method. This study confirms the fact that additional methods are recommended for mass surveys (Tchuem Tchuenté et al., 2012; Knopp et al., 2008 and WHO, 1983) and lead to suggest their systematic application in different hospitals.

the community level and chemotherapy. This work therefore highlights the need to educate members of the community, especially those in rural areas, on the preventing methods of transmission and spread of human intestinal parasite infections.

OMS, 1988. Importance des parasitoses intestinales en santé publique. Bulletin de l'Organisation mondiale de la santé, 12 (66): 23-34.

Ostan I, Kilimcioghu A A, Girginkardesler N, Ozurt B C and Limoncu M E, 2007. Health inequities lower socio-economic conditions and higher incidences of intestinal parasites. BMC public health, 7: 342-349.

Rodriguez-Morales A J, Barbella R A, Case c, et al, 2006. Intestinal parasitic among pregnant woman in Venezuela. Infect dis obstect, 123125.

OMS, 2017.Géohelminthiases.Aide-mémoire $\quad N^{\circ} 366$ http://www.who.int/mediacentre/

factsheets/fs366/frl. Page consultée le 25 juin 2017 à 16 heures.

Ouermi D, Karou D, Ouattara I, Gnoula C, Pietra V, Moret R, PignatelliS,Nikiema J B et Simpore J, 2012. Prévalence des parasites intestinaux de 1991 à 2010 au centre médical Saint-Camille de Ouagadougou (Burkina Faso). Medecine et Santé Tropicales, 22: 40-44.

Peruzzi S, Gorrini C, Piccolo G, Calderaro A, Dettori G and Chezzi C, 2006.Prevalence of intestinal parasites in the area of Parma during the year 2005. .ActualitésBiomedicales, 77: 147-51.

Benouis A, Bekkouche Z et Benmansour Z, 2013. Etude épidémiologique des parasitoses intestinales humaines au niveau du $\mathrm{CHU}$ d'Oran (Algérie). International Journal of Innovation and Applied Studies, 2(4): 613-620. 
Dianou D, Poda J-N, Savadogo L G, Sorgho H, Wango $S P$ et Sondo B, 2004. Parasitoses intestinales dans la zone du complexe hydroagricole du Sourou au Burkina faso.la revue en sciences de l'environnement, $2: 5 p$.

Tagajdid R, Lemkhente Z, Errami M, Mellouki W L et Mimouni B, 2012. Portage parasitaire intestinal chez l'enfant scolarisé à Salé, Maroc. Bulletin de la Société de pathologie exotique, 105 (1): 40-45.

Anonyme, 2017.Bamboutos. Wikipédia, l'encyclopédie libre.http://fr.wikipedia.org/w/index.php?title. Page consultée le 23 septembre 2017 à $15: 48$.

OMS, 1983. Cellophane fecal thick smear examination technique for diagnosis of intestinal schistosomiasis and gastrointestinal helminthiasis infections. WHO/CDS/SIP/82, 32p.

OMS, 1993. Infestation et anaemia ankylostomienne. Series de rapports techniques, 876: $57 \mathrm{p}$.

Katz N, Chaves A and Pellegrino J, 1972. A simple device for quantitative stool thick-smear technique in Schistosomiasis mansoni. Revista do Instituto de Medicina Tropical de Sao Paulo, 14:397-400.

Guillaume V, 2007. Parasitologie, fiches pratiques (Autoévaluation et Manipulation). Edition De boek et Laciers, 188p.

Fouamno Kamga H L, SheyNsagha D, SuhAtanga M B, Long dohNjunda A, NguediaAssob J C, Nde Fon $P$ and AkwiFomumbod S, 2011. The impact of health education on the prevalence of faecal-orally transmitted parasitic infections among school children in a rural community in Cameroon. Pan African Medical Journal, 8: $38 p$.

Lehman L G, Kouodjip Nono L and Bilong Bilong C F, 2012. Diagnostic des parasitoses intestinales à l'aide de la microscopie à fluorescence. Médecine Afrique Noire, 7 : 377-385.

Kostoingué $B$, Tidjani $M \mathrm{H}$, Francine $\mathrm{M}$ et Alio $\mathrm{H} \mathrm{M}$, 2002. Prévalence des parasitoses intestinales chez les enfants de 0-5 ans dans la ville de N'Djamena (Tchad). La Revue en Sciences de l'Environnement, 15 : 13-17.

Faye O, N'dir O, Gaye O, Dieng T, Bah B I etDiallo S, 1998. Les parasitoses intestinales dans le bassin du fleuve Sénégal. Résultats d'enquêtes effectuées en milieu rural. Médecine d'Afrique Noire, 45: 8-9.
Adoubryn K D, Kouadio-Yapo C G, Ouhon J, Aka N A D, Bintto $F$ et Assoumou A, 2012.Parasitoses intestinales infantiles à Biankouma, région des 18 Montagnes (ouest de la Côte d'Ivoire): étude de l'efficacité et de la tolérance du praziquantel et de l'albendazole.Médecine et Sante' Tropicales, $22: 170-176$.

Aksoy U, Akisu C, Tuncay S, Delibas S B, Iceboz T, Over $L$ and Oral A M, 2005. An Outbreak of Intestinal Protozoa Associated with Drinking Water. Journal of Science and Medicine, 73: 163-166.

Soumana A, Kamaye M, Saidou D, Dima H, Daouda B et Guéro T, 2016.Les parasitoses intestinales chez les enfants de moins de cinq ans à Niamey au Niger.mali médical tome xxxi, 4 : $9 P$.

Laamrani A I E, Idrissi A, Lyagoubi M, Barkia A, Ayoujil $M$ et Mahjour J, 1999. Prévalence des parasitoses intestinales au niveau de trois provinces au Maroc.Revue de la Santé méditerranéenne orientale, $1: 86-102$.

Hamit M A, Abdelsalam T, Brahim B O, Tidjani M T and Bilong Bilong C F, 2017. Prevalence of intestinal worms among school children in Chad: importance of highlighting the concentration method in faecal examination. Journal of Biology and Life Science, 7:418422.

Knopp S, Mgeni A F, Khamis I S, Steinmann P, Stothard J R, Rollinson D, Marti $H$ and Utzinger J, 2008. Diagnosis of SoilTransmitted Helminths in the Era of Preventive Chemotherapy: Effect of Multiple Stool Sampling and Use of Different Diagnostic Techniques. Neglected Tropical Diseases, 2: 331-345.

Tchuem Tchuenté L A, Romuald I K N, Sumo L, Ngassam $P$, Calvine D N, Deguy D L N, Dankoni $\mathrm{E}$, Kenfack C M, Feussom N G, Akame J, TariniA, Yaobi Zhang and Angwafo F, 2012. Mapping of Schistosomiasis and SoilTransmitted Helminthiasis in the Regions of Centre, East and West Cameroon. PLoS Neglected Tropical Diseases, 155-173. 